\title{
Chemical characteristics and enhanced hepatoprotective activities of Maillard reaction products derived from milk protein-sugar system
}

\author{
Nam Su Oh, ${ }^{* 1}$ Ji Young Lee, ${ }^{*}{ }^{1}$ Hyun Ah Lee, $\dagger$ Jae Yeon Joung, ${ }^{*}$ Yong Kook Shin, ${ }^{*}$ Sae Hun Kim, $\dagger$ \\ Younghoon Kim, $\ddagger^{2}$ and Kwang Won Lee ${ }^{2}$ \\ ${ }^{*}$ R\&D Center, Seoul Dairy Cooperative, Ansan, Kyunggi 425-839, South Korea \\ †Department of Biotechnology, College of Life Science \& Biotechnology, Korea University, Seoul 136-713, South Korea \\ łBK21 Plus Graduate Program, Department of Animal Science, Chonbuk National University, Jeonju, 561-756, Korea
}

ABSTRACT

The objective of this study was to investigate the characteristics, antioxidative properties, and hepatoprotective effects of Maillard reaction products (MRP) from milk protein reacted with sugars. The MRP were obtained from milk protein, whey protein concentrates and sodium caseinate, using 2 types of sugars, lactose and glucose, by heating the mixture at $55^{\circ} \mathrm{C}$ for $7 \mathrm{~d}$ in a sodium phosphate buffer ( $\mathrm{pH}$ 7.4). Changes in the chemical modification of the milk protein were monitored by measuring the protein-bound carbonyls and PAGE protein profiles. The results showed that the amount of protein-bound carbonyls increased after Maillard reaction (MR). In addition, sodium dodecyl sulfate-PAGE analysis indicated a formation of high-molecular weight complexes through MR. The modification sites induced by MR of milk protein were monitored by matrixassisted laser desorption/ionization time-of-flight mass spectrometry analysis of tryptic-digested gel spots of MRP. As a result, modification and their localization in AA sequence of MRP was identified. Also, the MRP showed higher antioxidant activities than the intact milk protein, and they reduced intracellular reactive oxygen species production and inhibited the depletion of the reduced glutathione concentrations in the HepG2 cells. In particular, glucose-sodium caseinate MRP showed the highest biological activities among all MRP. Therefore, these results suggest that the MRP from milk protein reacting with sugars possess effective antioxidant activity and have a protective ability against oxidative damage.

Key words: Maillard reaction, milk protein, antioxidant activity, hepatoprotective effect

\footnotetext{
Received June 25, 2015.

Accepted September 4, 2015.

${ }^{1}$ These authors contributed equally to this study.

${ }^{2}$ Corresponding authors: kwangwon@korea.ac.kr and ykeys2584@ jbnu.ac.kr
}

\section{INTRODUCTION}

Oxidative stress is known to play an important role in the development of several diseases, such as cancer, diabetes, neurodegenerative diseases, cardiovascular diseases, and chronic renal failure (Tiwari, 2004). The liver is particularly susceptible to toxic and oxidative damage, as the portal vein brings blood directly to this organ following intestinal absorption. Reactive oxygen species (ROS) and reactive nitrogen species have been shown to play a crucial role in disease induction and progression in liver diseases, such as hepatocarcinoma, viral or alcoholic hepatitis, and nonalcoholic steatohepatitis (Vidyashankar et al., 2010). Excessive ROS brings about oxidative stress and attacks cellular biomolecules, such as lipids, proteins, and DNA. This oxidative stress-induced damage can disrupt cellular functions and membrane integrity, thereby leading to cell death. Because damage to the liver inflicted by oxidative stress has serious consequences, several dietary antioxidants have been proposed as therapeutic agents to reduce oxidative stress and improve liver function (Vitaglione et al., 2004).

The Maillard reaction (MR), defined as nonenzymatic browning, involves sugars and the AA of proteins. These compounds condense and progress into a complex network of reaction products, which are collectively known as Maillard reaction products (MRP; Lederer and Bühler, 1999). Whereas MRP can be harmful to health, many recent studies have reported that MRP also have beneficial effects, such as antioxidant, antimicrobial, anticarcinogenic, and antitumoral properties (Rufián-Henares and Morales, 2006). In the case of dairy products, a potential role for the antioxidative properties of MRP derived from milk proteins has been investigated extensively (Liu et al., 2012; Wang et al., 2013; Zhao et al., 2013). Importantly, our group has reported previously that the biological characteristics and antioxidant activity of milk proteins were improved by the combination of the MR and enzymatic hydroly- 
sis (Oh et al., 2013). We also reported that MRP and fermented MRP reduced cardiovascular risk in in vitro and in vivo studies (Oh et al., 2014, 2015).

With increasing interest being given to the biological effects of MRP, it is necessary to study the chemical modification of MRP. Matrix-assisted laser desorption/ ionization time-of-flight/mass spectrometry (MALDITOF/MS) has recently become a widely used analytical technique for determining increased protein mass that might be correlated with MR due to its excellent sensitivity, relatively high speed, and simplicity (Humeny et al., 2002). However, few studies have shown a correlation between the chemical structure changes of Maillard-reacted proteins and biological functionality.

Most studies on milk proteins have focused on the evaluation of their bioactivities using chemical methods in vitro. Studies on the effect of Maillard-reacted milk protein on living cells are limited. There are few reports regarding the antioxidant and hepatoprotective effects of MRP that are formed using the milk protein-sugars model. Thus, the purposes of our study were (1) to determine the characteristics and chemical modifications of milk protein when Maillard reacted with sugars and (2) to investigate their antioxidant properties and hepatoprotective activities against oxidative damage. This study was performed using cultured HepG2 cells of human origin.

\section{MATERIALS AND METHODS}

\section{Chemicals}

Whey protein concentrates (WPC) and sodium caseinate (SC) were obtained from Davisco Foods International Inc. (Le Sueur, MN) and Kerrygold (Dublin, Ireland). Sequencing-grade trypsin was obtained from Roche (Mannheim, Germany).

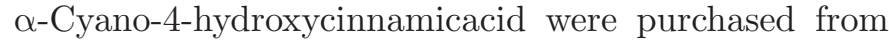
Bruker (Bremen, Germany). The chemicals, including 2,2'-azino-bis(3-ethylbenzothiazoline-6-sulfonic acid) diammonium salt (ABTS), potassium persulfate, 2,4,6'-tripyridyl-s-triazine (TPTZ), 1,1'-diphenyl2-picrylhydrazyl (DPPH), L-ascorbic acid, iron (III) chloride hexahydrate, thiazolyl blue tetrazolium blue (MTT), tert-butyl hydroperoxide ( $\boldsymbol{t}$-BHP), 2',7-dichlorofluorescin diacetate (DCFH-DA), dithiothreitol, iodoacetamide, ammonium bicarbonate, urea, and trifluoroacetic acid used in this study were purchased from Sigma Chemical Co. (St. Louis, MO). Minimum essential medium (MEM), antibiotic antimycotic solution, trypsin-EDTA, and BSA were obtained from Thermo Scientific (Logan, UT). All others reagents were analytical grade.

\section{Preparation of MRP Derived from Milk Protein}

The milk protein (WPC and SC) and sugars (lactose and glucose) were dissolved in $0.1 M$ sodium phosphate buffer $(\mathrm{pH} 7.4)$ at a 1:5 weight ratio of protein (20 $\mathrm{mg})$ and sugar $(100 \mathrm{mg})$. Four samples were prepared: lactose-WPC (L-wMRP), glucose-WPC (G-wMRP), lactose-SC (L-cMRP), and glucose-SC (G-cMRP). The reaction was allowed to proceed at $55^{\circ} \mathrm{C}$ for $7 \mathrm{~d}$. The $\mathrm{pH}$ value was not controlled during the reaction. Prior to freeze drying, the MR solution was extensively dialyzed against $0.1 M$ sodium phosphate buffer $(\mathrm{pH}$ 7.4) using a dialysis tube (molecular weight cut-off $=$ 3,500 ) for $24 \mathrm{~h}$, and the lyophilized MRP was used for further experiments.

\section{Characterization of MRP}

Measurement of Fluorescence. The fluorescence intensity for MRP was measured at an excitation of 370 $\mathrm{nm}$ and an emission of $440 \mathrm{~nm}$ with a Synergy H1 plate reader (Bio-Tek Instruments Inc., Winooski, VT).

Protein-Bound Carbonyls. Protein-bound carbonyls were determined according to the method of Levine et al. (1990). Determination of carbonyl content in oxidatively modified proteins were performed by the method of Cucu et al. (2011) with slight modifications. The carbonyl content was calculated using a molar absorption coefficient of $22,000 M^{-1} \mathrm{~cm}^{-1}$.

$\boldsymbol{S D S} \boldsymbol{P} \boldsymbol{A} \boldsymbol{G E}$. The MRP were analyzed by SDSPAGE, carried out according to the procedure of Laemmli (1970) as described previously. Protein concentration was quantified using a Synergy H1 plate reader with the Take3 microdrop addition (Bio-Tek Instruments Inc.). Sample solutions (60 $\mu \mathrm{g}$ of protein) were loaded on $15 \%$ Ready Gel Tris-HCl Gel (Bio-Rad, Hercules, CA). After electrophoresis, gels were stained to visualize protein bands using Coomassie Brilliant Blue R-250 Staining Solution (Bio-Rad). Subsequently, glycoproteins were detected after development with a carbohydrate staining dye (Glycoprotein Staining Kit; Thermo Scientific, Rockford, IL).

\section{In-Gel Digestion}

The in-gel tryptic digestion was by slightly modified method of Shevchenko et al. (2006). At first, the spots of interest were cut in small pieces that were washed with deionized water and destained with 100 $\mathrm{m} M \mathrm{NH}_{4} \mathrm{HCO}_{3}$ in $50 \%$ acetonitrile $(\mathbf{A C N})$ for $30 \mathrm{~min}$. The gel pieces were dried in speed vacuum and dehydrated with 100\% ACN. Proteomics grade trypsin (1:50

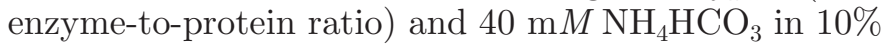


$\mathrm{ACN}$ were incubated at $37^{\circ} \mathrm{C}$ overnight. After incubation, the digested samples were extracted twice with $5 \%$ formic acid in $50 \% \mathrm{ACN}$ and purified by ZipTip $\mathrm{C}_{18}$ (Millipore, Bedford, MA).

\section{MALDI-TOF/MS and MS/MS Analysis}

For peptide analysis, the peptide samples were mixed with an equal volume of matrix solution ( $\alpha$-cyano-4hydroxycinnamicacid) and $1 \mu \mathrm{L}$ was spotted onto MALDI target. The MALDI-TOF/MS experiments were performed using a Bruker Autoflex (Bruker Daltonics, Bremen, Germany) equipped with a nitrogen laser (337 $\mathrm{nm}$ ). Laser-desorbed positive ions were analyzed after acceleration by $19 \mathrm{kV}$ in the reflector mode for peptide digest. External calibration was performed using a mix of angiotensins I and II, substance P, bombesin, adrenocorticotropic hormone (ACTH) clips 1-17 and 18-39, and somatostatin 28 for the digest. For each displayed mass spectrum, at least 500 laser shots from several positions on the spots were collected.

\section{Database Search}

The mass spectra obtained from enzymatic digest of MRP were searched against the nonredundant database Swiss-Prot utilizing Mascot (Matrix Science Ltd., London, UK). The search was performed against the Other Mammalia (or Bos taurus) database (www.matrixscience.com), setting the following modifications: carbamidomethylation as a fixed modification and lactosylation, glycation as a variable modification.

\section{Antioxidant Capacity}

The capacity of MRP to scavenge free radicals was assessed using the ABTS and DPPH assay (Blois, 1958). The results were reported as the concentration of sample required to scavenge $50 \%$ of radical $\left(\mathbf{I C}_{50}\right)$, whereas the reducing power of MRP was determined by the ferric reducing ability of plasma (FRAP) assay (Benzie and Strain, 1996). The FRAP value was calculated using the calibration curve of $\mathrm{FeSO}_{4}$, a standard reducing agent allowing the transition from TPTZ$\mathrm{Fe}(\mathrm{III})$ to TPTZ-Fe(II).

\section{Cell Culture and Cell Treatment}

The human hepatoma cell line, HepG2 (KCLB No. 58065) was purchased from the Korea Cell Line Bank (Seoul, Korea). HepG2 cells were cultured in MEM containing $10 \%$ heat-inactivated fetal bovine serum, $1.0 \%$ antibiotic-antimycotic solution in a humidified
$5.0 \% \mathrm{CO}_{2}$ at atmosphere $37^{\circ} \mathrm{C}$. To study the hepatoprotective effects of MRP, HepG2 cells were pretreated with different concentration of MRP for $20 \mathrm{~h}$. Then, the medium was discarded fresh medium containing 500 $\mu M \mathrm{t}-\mathrm{BHP}$ was added to all the cultures except controls for $3 \mathrm{~h}$.

\section{Evaluation of Cytotoxicity and Hepatoprotective Effect}

Cytotoxicity and hepatoprotective effect were evaluated by MTT assay as previously described (Mosmann, 1983). Briefly, HepG2 cells were seeded in 96-well plates at $1 \times 10^{5}$ cells per well. After treatment, $0.5 \mathrm{mg} / \mathrm{mL}$ of MTT reagent, dissolved in MEM, was added to each well and the cells were incubated for $3 \mathrm{~h}$ at $37^{\circ} \mathrm{C}$. Then, the medium was removed and $200 \mu \mathrm{L}$ of dimethyl sulfoxide (DMSO) were added to each well to solubilize the formazan product. The absorbance was measured at $540 \mathrm{~nm}$. The relative cell viability of HepG2 cells of after treatment was determined using the followed formula:

Cell viability $(\%)=\frac{\text { absorbance } 540 \mathrm{~nm}(\text { treatment })}{\text { absorbance } 540 \mathrm{~nm}(\text { control })} \times 100$.

\section{Determination of ROS Generation}

The production of intracellular ROS was measured by using DCFH-DA fluorescent probe, as previously described Wang and Joseph (1999). For the assay, HepG2 cells were seed in 48 -well plates at $2.5 \times 10^{5}$ cells per well and pretreated with the different concentrations of MRP the day after. Twenty hours later, cells were washed and exposed to $20 \mu M$ DCFH-DA fluorescent dye for $30 \mathrm{~min}$ at $37^{\circ} \mathrm{C}$ in dark. Then, the cells were treated with $500 \mu M$ t-BHP in FBS-free medium except the control. The production of intracellular ROS was followed over $3 \mathrm{~h}$, the control was attributed the index value of 100 . The fluorescence intensity was measured at excitation $435 \mathrm{~nm}$ and emission $535 \mathrm{~nm}$ using Synergy H1 plate reader (Bio-Tek Instruments Inc.).

\section{Determination of Reduced Glutathione}

Cells were seeded in 6 -well plates at $1.5 \times 10^{6}$ cells per well. After treatment, the cells were collected by a scraper and lysed using a sonicator. The lysates were used for the reduced glutathione (GSH) assay. Intracellular GSH contents were measured using the Cayman's GSH assay kit (Ann Arbor, MI), which measures GSH in the basis of the 5,5'-dithiobis-(2-nitrobenzoic 


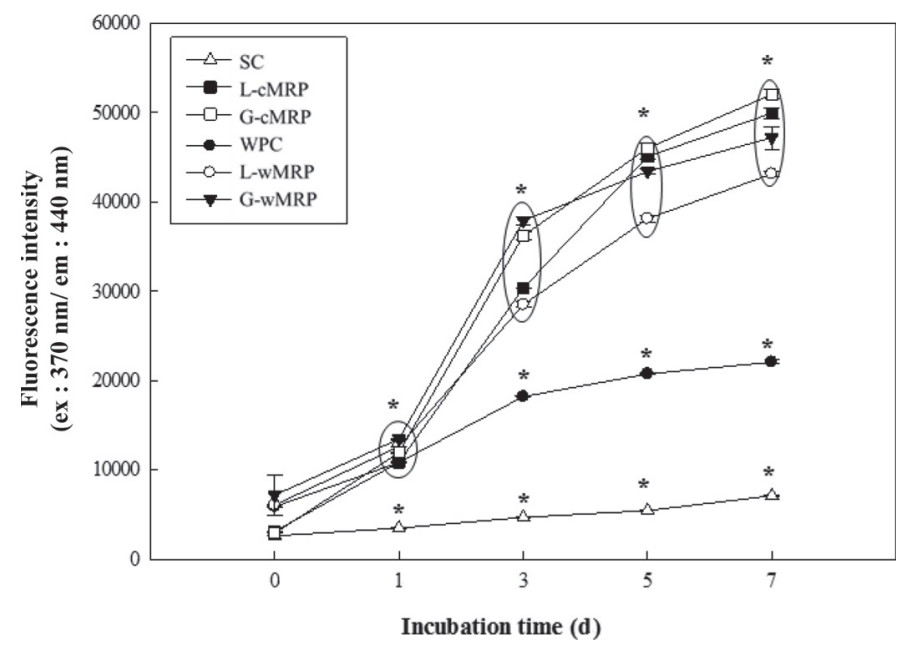

Figure 1. Fluorescence changes in Maillard-reacted milk protein with sugars during heating at $55^{\circ} \mathrm{C}$ for $7 \mathrm{~d}$. The results are presented as mean $\pm \mathrm{SD}(\mathrm{n}=3)$. An asterisk $(*)$ represents $P<0.05$, statistically significant compared with $0 \mathrm{~d}$ values. $\mathrm{SC}=$ sodium caseinate; $\mathrm{L}-\mathrm{cMRP}=$ lactose-SC Maillard reaction products (MRP); G-cMRP $=$ glucose-SC MRP; WPC $=$ whey protein concentrates; L-wMRP = lactose-WPC MRP; G-wMRP = glucose-WSC MRP.

acid)-glutathione reductase recycling reaction. The sulfhydryl group of GSH reacts with 5,5'-dithiobis-(2nitrobenzoic acid) (Ellman's reagent) and produces a yellow-colored 5-thio-2-nitrobenzoic acid (TNB). The mixed compound glutathione-TNB that is concomitantly produced is reduced by glutathione reductase to recycle the GSH and produce more TNB. The rate of TNB production is directly proportional to the concentration of GSH in the sample (Eyer and Podhradský, 1986). The GSH in the sample was determined by measuring the absorbance of TNB at $405 \mathrm{~nm}$. The level of GSH in the control was designated $100 \%$, was used to calculate the relative level of GSH in other groups.

\section{Statistical Analysis}

All data were expressed as means \pm SD. Statistical significance for the differences between the groups was assessed using Duncan's multiple range tests. We used SAS software version 9.2 (SAS Institute Inc., NC) to perform all statistical tests. Values of $P<0.05$ were considered to indicate a significant difference.

\section{RESULTS AND DISCUSSION}

\section{Characteristics of MRP}

The development of the fluorescent compounds of MRP with different sugars is shown in Figure 1. These fluorescent compounds are not only the precursors, but also the final products of the reaction (Matiacevich et al., 2005). As expected, the fluorescence intensity of the MRP increased gradually during the 7 -d heating period, and the rate of fluorescent development was higher in the MRP with glucose than in the MRP with lactose.

The interaction of reducing sugars might lead to the formation of protein bound carbonyls. Indeed, their reaction with the side chain of proteins gives rise to the Amadori reaction products (Stadtman and Levine, 2003). Therefore, the amount of protein-bound carbonyls was used as an indicator of the degree of MR. An increase in the amount of protein-bound carbonyls due to incubation of milk proteins with sugars was observed (Figure 2). In particular, the incubation of SC in the presence of sugars led to about a 4 -fold increase in protein-bound carbonyls compared with intact SC. Protein-bound carbonyls were formed in parallel with the fluorescent compounds in MRP (Figure 1). Similar results were reported in which the amount of proteinbound carbonyls increased after incubating BSA with glucose and fructose (Liggins and Furth, 1997).

\section{SDS-PAGE Analysis of MRP}

To further verify whether the sugars were conjugated with the milk protein, the patterns of the milk proteins were investigated using SDS-PAGE. The gels were stained with Coomassie Brilliant Blue R-250 (Bio-Rad) for total protein (Figure 3A), and the same gel was

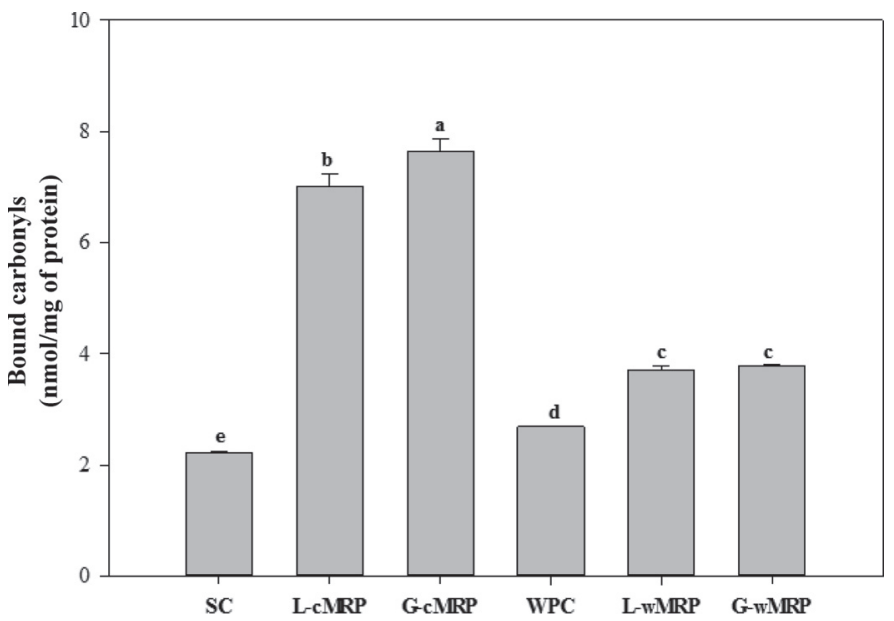

Figure 2. Formation of protein bound carbonyls in Maillardreacted milk protein with sugars during heating at $55^{\circ} \mathrm{C}$ for $7 \mathrm{~d}$. The results are presented as mean $\pm \mathrm{SD}(\mathrm{n}=3)$. Different letters $(\mathrm{a}-\mathrm{e})$ indicate statistically significant differences among the different groups $(P<0.05) . \mathrm{SC}=$ sodium caseinate L-cMRP $=$ lactose-SC Maillard reaction products $(\mathrm{MRP}) ; \mathrm{G}-\mathrm{cMRP}=$ glucose-SC $\mathrm{MRP} ; \mathrm{WPC}=$ whey protein concentrates; L-wMRP = lactose-WPC MRP; G-wMRP = glucose-WSC MRP. 

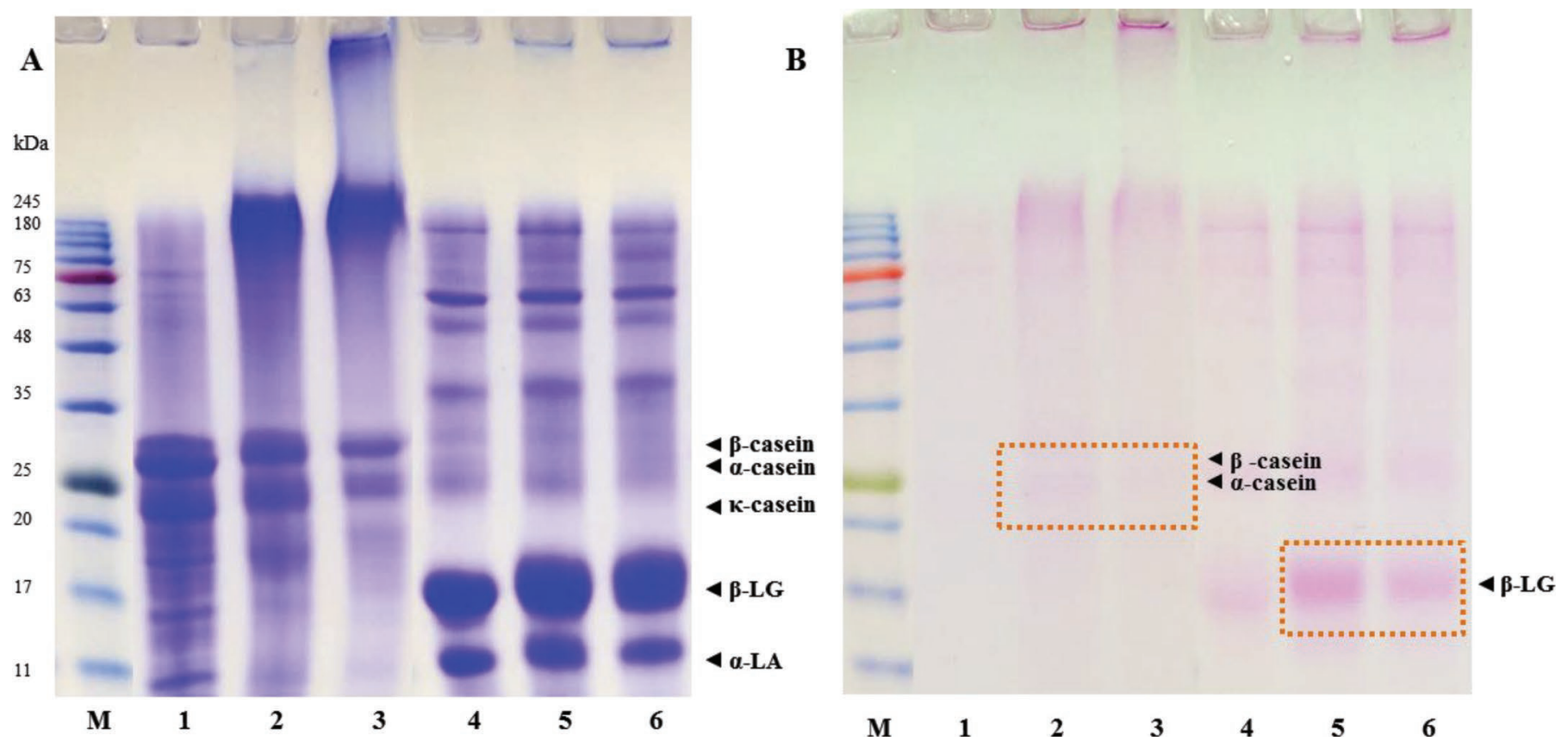

Figure 3. The SDS-PAGE gel after (A) protein staining and (B) glycoprotein staining of intact milk protein and Maillard-reacted milk proteins (MRP). $\mathrm{M}=$ size marker; lane $1=$ sodium caseinate $(\mathrm{SC})$; lane $2=\mathrm{L}$-cMRP; lane3 = G-cMRP; lane $4=\mathrm{WPC}$; lane $5=\mathrm{L}$-wMRP; lane $6=\mathrm{G}$-wMRP; SC = sodium caseinate; L-cMRP = lactose-SC Maillard reaction products $(\mathrm{MRP}) ; \mathrm{G}-\mathrm{cMRP}=\mathrm{glucose}-\mathrm{SC}$ MRP; WPC $=$ whey protein concentrates; L-wMRP = lactose-WPC MRP; and G-wMRP = glucose-WPC MRP. Color version available online.

stained using the periodic acid-Schiff method to visualize glycated proteins (Figure 3B). After the MR of the milk protein and sugars, dense bands were observed for MRP at the boundary stacking and separating gel (Figure 3A; lanes 2, 3, 5, and 6). This result was in accordance with our previous study, which reported that Maillard-reacted milk protein generated higher molecular materials (Oh et al., 2013). The same band was also observed under glycoprotein staining (Figure $3 \mathrm{~B}$; lanes 2, 3, 5, and 6). The new smearing pattern of Maillard-reacted milk protein in Figure 3B (lanes $2,3,5$, and 6 ) indicates the formation of a sugar-milk protein conjugate compared with intact milk protein.

The major proteins of WPC ( $\beta$-LG and $\alpha$-LA) and $\mathrm{SC}(\alpha-, \beta-$, and $\kappa-\mathrm{CN})$ were clearly observed in all samples. However, the band intensity of major proteins decreased via MR. The relative loss of the native form of milk proteins was different depending on whether the milk proteins were incubated with lactose and glucose (Figure 3A; lanes 2 and 3). In particular, $\beta$ - and $\kappa-\mathrm{CN}$ in Maillard-reacted SC (cMRP) were diminished. These results correspond to the high-molecular weight protein polymers generated from cMRP and suggest that the MRP were generated more from SC than from WPC. Similar results were reported in a study in which glycated $\beta$-CN appeared faster than $\beta$-LG when heating was performed in the presence of glucose (Pinto et al.,
2014). In addition, the molecular weights of $\beta$-LG and $\alpha$-LA appeared to increase slightly (Figures 3A and 3B; lanes 5 and 6 ), which might be attributed to the high degree of MR upon incubating WPC and sugars. Overall, these results of SDS-PAGE patterns are in line with all other parameters assessed to monitor the progress of MR upon incubating the milk proteins and sugars.

\section{MALDI-TOF/MS Analysis of MRP after Partial Enzymatic Hydrolysis}

Recent studies have reported the use of MALDITOF/MS to determine the increase in the mass of MRP (Humeny et al., 2002). Maillard reaction involving milk proteins and sugars resulted in the formation of new compounds, as indicated by SDS-PAGE in our study. To verify further the possible MR-induced chemical modification, we examined the protein extracted from SDS-PAGE gel spots relevant to MRP using MALDITOF/MS. After incubating milk proteins with lactose and glucose for $7 \mathrm{~d}$, newly formed multiple adduct mass shifts appeared in the spectra of the intact protein (data not shown). To get more detailed insight into the site of the modifications, the Maillard-reacted milk proteins were digested using trypsin, which cleaves peptide chains mainly at the carboxyl side of the lysine or arginine, before mass spectrometric analysis. 
Figure 4 represents the MALDI-TOF/MS and MS/ MS spectra of the tryptic digestion of Maillard-reacted WPC (wMRP). The $\beta$-LG peptide ${ }^{117}$ KYLLFCMENSAEPEQSLACQCLVR ${ }^{140}$ with lactose adducted on $\mathrm{K}^{117}$ and a modified mass of 3271.359 was detected (Figure 4A). Figure 4B shows that $\mathrm{m} / z 3,108.140$ was observed in the same $\beta$-LG peptide sequence (AA 117140), which could correspond to the addition of glucose on $\mathrm{N}^{125}$. Also, glucose adduct was detected at $\mathrm{m} / \mathrm{z}$ $1,312.097$ involving $\mathrm{K}^{157}$, and a $\beta$-LG peptide sequence corresponding to adduct with glucose was identified as ${ }^{155}$ ALKALPMHIR $^{164}$. Calvano et al. (2013) and similar studies reported that modification (i.e., lactosylation and generation of $\mathrm{N}^{\varepsilon}$-carboxymethyllysine) of powdered milk occurred in $\beta$-LG peptide ALKALPMHIR.

The MALDI-TOF/MS and MS/MS spectra of the tryptic digests of $\alpha$ - and $\beta$-CN excised from the SDSPAGE gel spots of cMRP are shown in Figure 5. The $\alpha$-CN peptide ${ }^{140}$ EGIHAQQKEPMIGVNQELAYFYPELFR $^{166}$ with lactose and glucose adduct on the same site, $\mathrm{K}^{147}$, and the modified peptide were detected at $m / z 3,531.794$ and $3,027.536$, respectively (Figure 5A and $\mathrm{C}$ ). Additionally, the $\beta$-CN peptide adducted on lactose (modified peptide $m / z 3,081.597$ ) were identified in the AA sequence ${ }^{192}$ AVPQRDMPIQAFLLYQEPVLGPVR $^{215}$, and the modification site was $\mathrm{R}^{196}$ (Figure $5 \mathrm{~B})$. Also, the formation of the glucose adduct was observed for the peptide ${ }^{185}$ VLPVPQKAVPYPQR ${ }^{198}$ from $\beta$-CN (modified peptide $m / z$ 1,754.050), indicating glucose adduct at $\mathrm{K}^{191}$ (Figure 5D). The identification of peptides modified by MR has been reported by other researchers (Meltretter et al., 2007; Calvano et al., 2013); however, the identity of the modified $\alpha$-LA and k-CN peptides could not be confirmed in this study. This discrepancy may be explained by the use of different sugars, heating conditions, and enzymatic digestion conditions.

We confirmed that the Maillard-reacted modification occurred in $\beta-\mathrm{LG}$ and $\alpha-$ and $\beta-\mathrm{CN}$. This result was in agreement with the glycoprotein-stained SDS-PAGE gel, which revealed that the $\beta-\mathrm{LG}$ and $\alpha-$ and $\beta-\mathrm{CN}$ participated mainly in the MR of milk proteins.

\section{Antioxidant Capacity of MRP}

The antioxidant activities in the present study were assessed using DPPH, ABTS, and FRAP assays. Both DPPH and ABTS are decolorization assays that measure the relative antioxidant abilities of natural extracts to scavenge the free radicals generated in the assay system (Apak et al., 2007). The $\mathrm{IC}_{50}$ values are the MRP concentrations required to scavenge $50 \%$ of the free radicals; they are presented in Figure $6 \mathrm{~A}$ and 4B. The results indicated that the ABTS radical and
DPPH scavenging activities of the MRP from milk proteins improved dramatically. In particular, G-cMRP was the most effective ABTS radical scavenger, with the lowest $\mathrm{IC}_{50}$ values $(6.37 \pm 0.14 \mathrm{mg} / \mathrm{mL})$, followed by L-cMRP, G-wMRP, and L-wMRP. Either of the intermediates of the final brown polymer can function as a hydrogen donor and contribute to the antiradical activity measured by DPPH assay (Benjakul et al., 2005). Therefore, these results indicate that MRP possesses a hydrogen-donating ability, suggesting that they have the potency to react with free radicals.

The reducing power of the MRP from milk protein is shown in Figure 6C. Reducing power is used to evaluate the ability of an antioxidant to donate an electron of hydrogen. The reducing power of the milk protein increased significantly with the MR. The greatest reducing power was observed in the G-cMRP $\left(106.40 \pm 1.41 \mu M \mathrm{FeSO}_{4} \cdot 7 \mathrm{H}_{2} \mathrm{O} / \mathrm{mg}\right.$ of protein), which showed an increase in reducing power that was 9.33 times greater than that of the intact SC. It has been reported that MRP could function as electron donors and that hydroxyl groups of MRP play an important role in reducing activity (Yoshimura et al., 1997). Similar research has reported that water-soluble MRP from the reactions between whey protein isolate and various sugars exhibited high antioxidant activity (Wen-qiong et al., 2013). Maillard reaction is a chemical method that has been reported to improve free radical scavenging activities and reduce the power and iron-chelating activities of protein hydrolysates (Liu et al., 2012). In the current study, the formation of MRP increased free radical scavenging activity and reduced power. Therefore, these results suggest that functional antioxidant activity proteins could be produced by through MR.

\section{Cytotoxicity and the Hepatoprotective Effect of MRP}

In our study, the cytotoxic and hepatoprotective effects of MRP were evaluated in HepG2 cells using an MTT assay, which can be reduced to purple formazan by dehydrogenase enzymes found in metabolically active cells. The human hepatoma cell line HepG2 is considered a good model with which to study in vitro toxicity of the liver, as it retains many of the specialized functions that are characteristic of normal human hepatocytes (Knasmüller et al., 1998). To select the appropriate concentrations of MRP for the cytoprotective study, the noncytotoxic concentrations were determined first. Samples up to $3.0 \mathrm{mg} / \mathrm{mL}$ had no effect on the cell viability $(\geq 85 \%)$ of HepG2 after 20 h of treatment (data not shown). Therefore, the concentrations of MRP finally selected $(0.5-3.0 \mathrm{mg} / \mathrm{mL})$ were used to evaluate further whether the MRP from milk protein were able to protect the HepG2 cells against $t$-BHP- 
induced oxidative stress. tert-Butyl hydroperoxide is an organic hydroperoxidant that can subsequently initiate lipid peroxidation, affect cell integrity, and form covalent bonds with cellular molecules, resulting in cell injury (Rush et al., 1985). In the present study, HepG2 cells were treated with MRP for $20 \mathrm{~h}$, after which the cells were exposed to $t$-BHP for $3 \mathrm{~h}$. As shown in Figure 7 , pretreatment of the MRP increased cell viability in

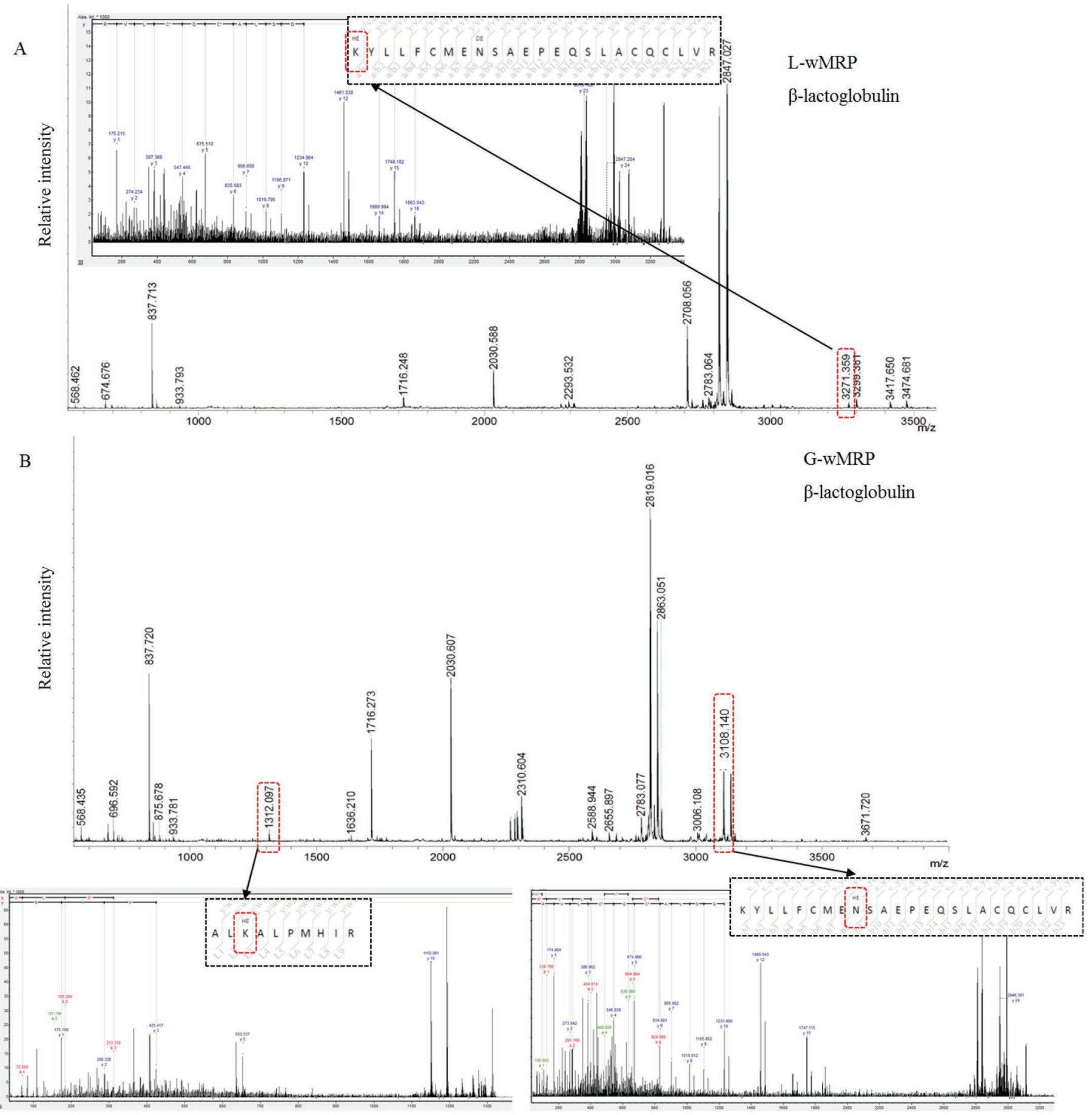

Figure 4. Matrix-assisted laser desorption/ionization time-of-flight/mass spectrometry and MS/MS spectra of the tryptic digests of $\beta$-LG excised from the SDS-PAGE gel spots of (A) lactose-whey protein concentrates Maillard reaction products (L-wMRP) and (B) glucose-whey protein concentrates Maillard reaction products. The Maillard-reacted peptides and sites are marked with a dotted square. Color version available online. 

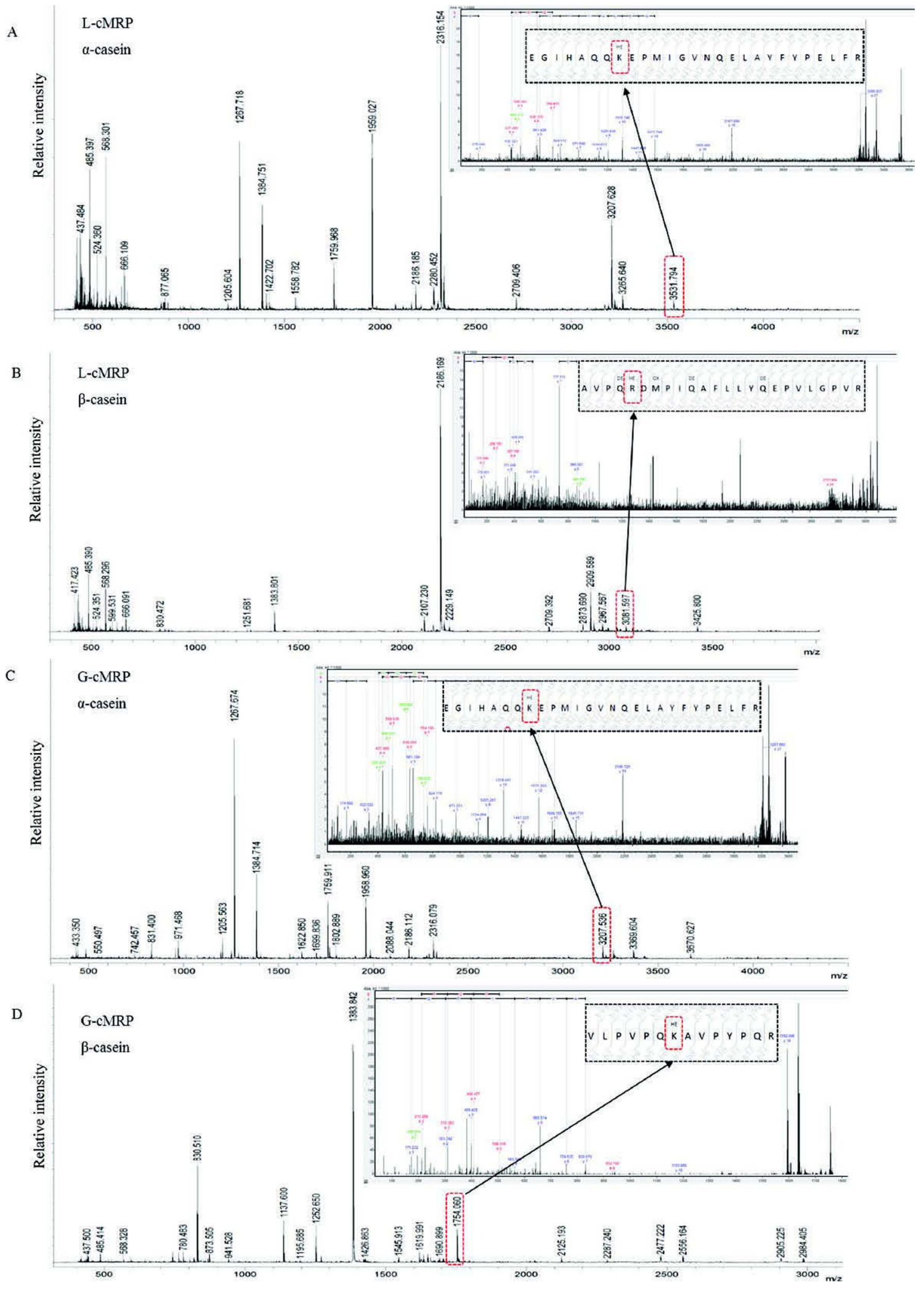

Figure 5. Matrix-assisted laser desorption/ionization time-of-flight/mass spectrometry and MS/MS spectra of the tryptic digests of (A) $\alpha-C N$ and (B) $\beta$-CN excised from the SDS-PAGE gel spots of lactose-sodium caseinate Maillard reaction products and (C) $\alpha-C N$ and (D) $\beta-C N$ excised from the SDS-PAGE gel spots of glucose-sodium caseinate Maillard reaction products. The Maillard-reacted peptides and sites are marked with a dotted square. Color version available online. 

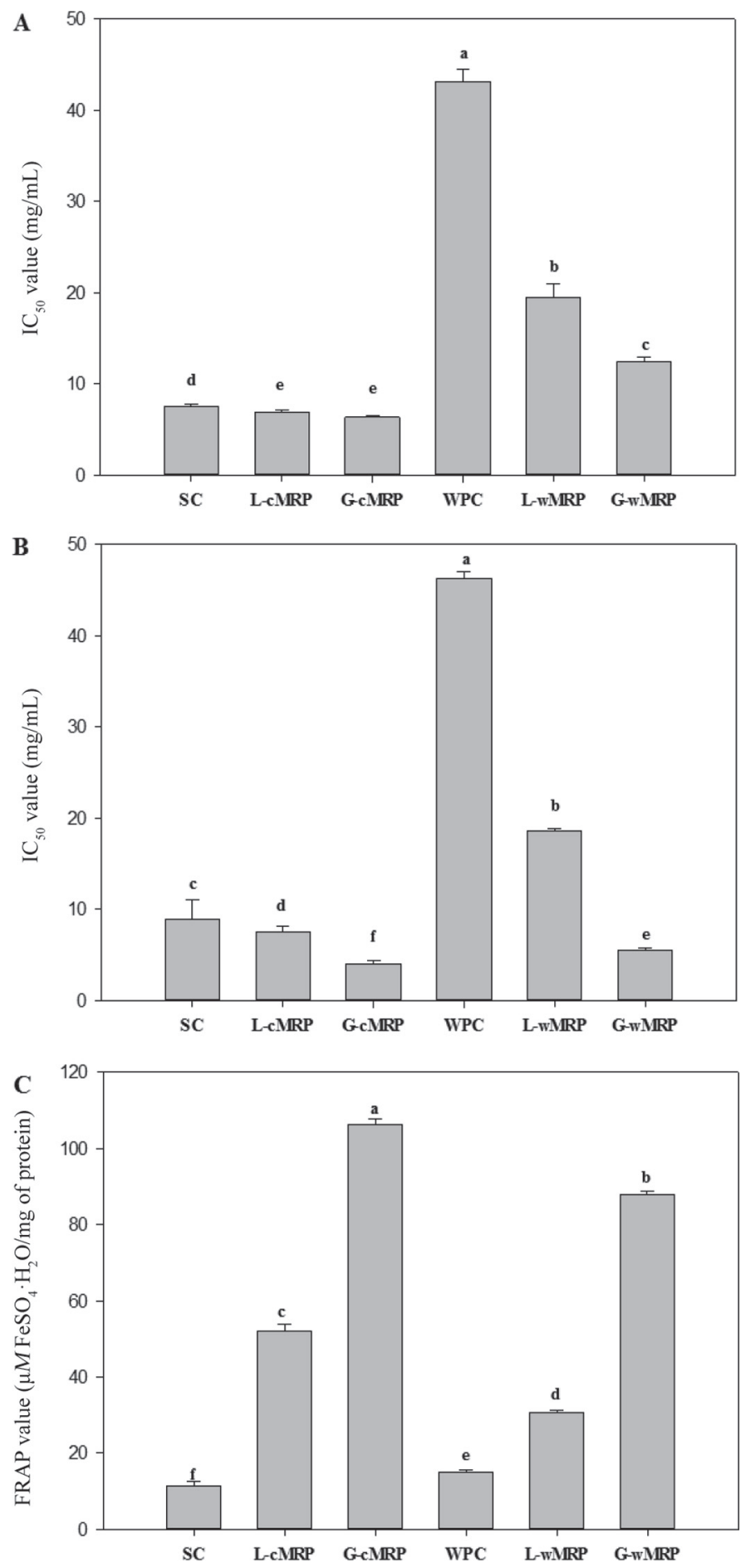

Figure 6. The (A) $\mathrm{ABTS}^{+}\left[2,2^{\prime}\right.$-azino-bis(3-ethylbenzothiazoline6-sulfonic acid) diammonium salt] radical-scavenging activity, (B) DPPH (1,1'-diphenyl-2-picrylhydrazyl) radical-scavenging activity, and $(\mathrm{C})$ ferric reducing ability of plasma (FRAP) value of Maillardreacted milk protein (MRP) with sugars. Different letters (a-f) indicate statistically significant differences among the different groups $(P$ $<0.05) . \mathrm{SC}=$ sodium caseinate; $\mathrm{L}-\mathrm{cMRP}=$ lactose-SC Maillard reaction products (MRP); G-cMRP $=$ glucose-SC MRP; $\mathrm{WPC}=$ whey protein concentrates; L-wMRP = lactose-WPC MRP; G-wMRP = glucose-WSC MRP.
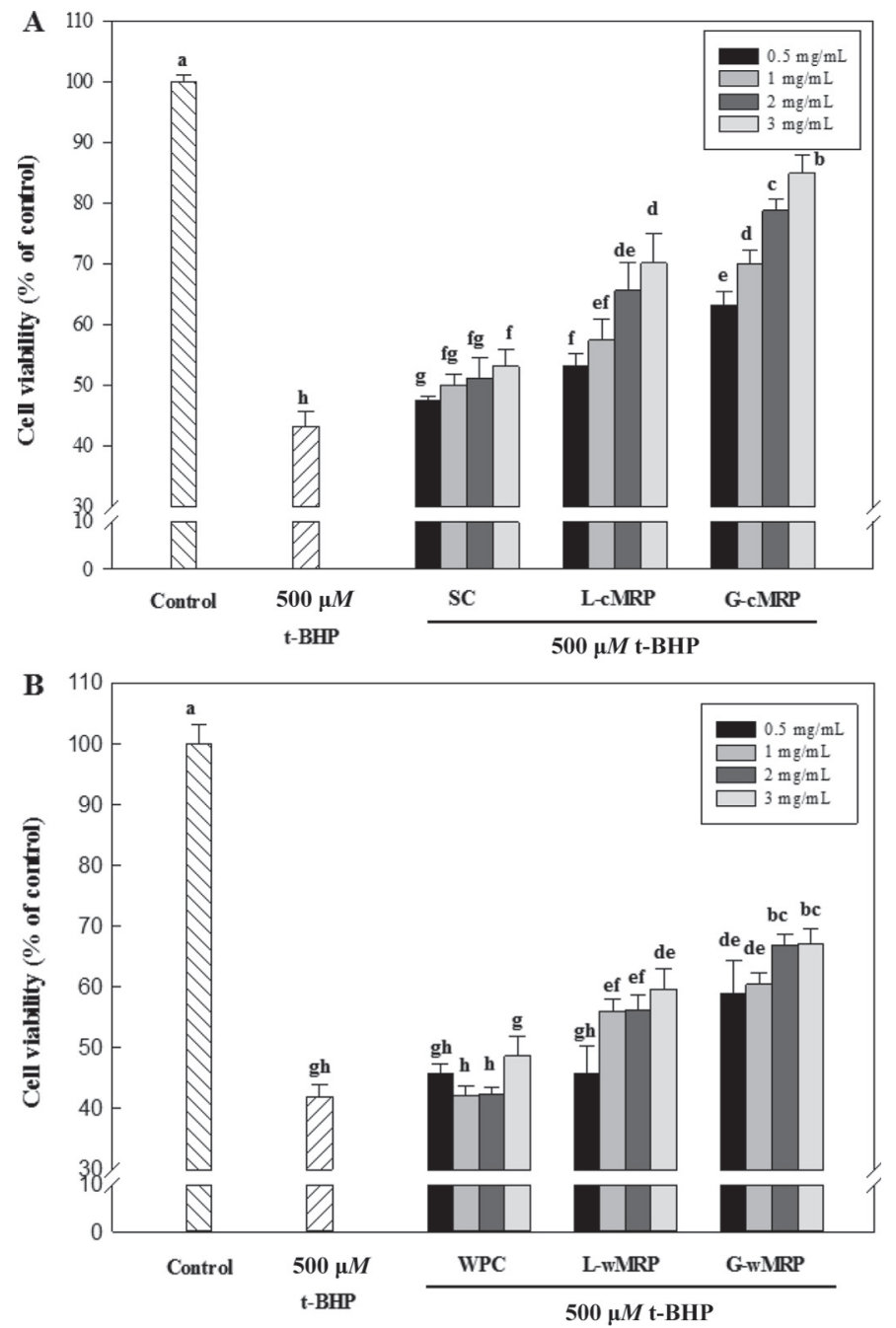

Figure 7. Effects of Maillard-reacted milk proteins (MRP) viability in $500 \mu M$ tert-butyl hydroperoxide ( $t$-BHP) induced HepG2 cells. The cells were pretreated with different concentrations of MRP for 20 $\mathrm{h}$ and exposure to $500 \mu \mathrm{Mt}$-BHP for $3 \mathrm{~h}$. The results are presented as mean $\pm \mathrm{SD}(\mathrm{n}=3)$. Different letters $(\mathrm{a}-\mathrm{g})$ indicate statistically significant differences among the different groups $(P<0.05) . \mathrm{SC}=$ sodium caseinate; L-cMRP = lactose-SC Maillard reaction products (MRP); $\mathrm{G}$-cMRP $=$ glucose-SC MRP; WPC $=$ whey protein concentrates; $\mathrm{L}-\mathrm{wMRP}=$ lactose-WPC MRP; G-wMRP $=$ glucose-WSC MRP.

a dose-dependent manner compared with intact milk protein. In particular, cMRP had the best hepatoprotective effect. The viability of the cMRP-pretreated cells increased up to 70 to $84 \%$ at $3.0 \mathrm{mg} / \mathrm{mL}$.

\section{Decreased ROS Generation by MRP}

To evaluate the degree of cellular oxidative stress, intracellular ROS production was estimated using a DCFH-DA assay. The HepG2 cells were pretreated with MRP for $20 \mathrm{~h}$, after which $500 \mu M t$-BHP were added for $3 \mathrm{~h}$. tert-Butyl hydroperoxide can decompose 
to peroxyl radicals and generate lipid peroxidation and ROS, thus increasing fluorescence (LeBel et al., 1992). The cells treated with $t$-BHP showed an increase in ROS generation that was 1.7 times greater than that of the nonstressed control. As shown in Figure 8, all of the samples inhibited ROS generation in a dose-dependent manner compared with those that were $t$-BHP treated. Remarkably, pretreatment with G-sMRP decreased ROS generation significantly, to nearly that of the control values, and it was the most efficient for reducing the ROS values (Figure 8A). The direct evaluation of ROS yields provides a good indication of the oxidative damage to living cells. High levels of ROS are thought to be a major cause of intracellular damage, leading to cell aging and age-related degenerative diseases (Halliwell et al., 1992). However, milk protein protects cells against oxidative damage by scavenging free radicals and inhibiting lipid peroxidation (Zhao et al., 2013). In our study, the increased ROS generation in cultured HepG2 cells subjected to oxidative stress by $t$-BHP was completely inhibited by pretreatment for $20 \mathrm{~h}$ with a dose of MRP.

\section{Reduced Glutathione Concentrations by MRP}

Reduced GSH concentrations were measured in cells as an index of intracellular nonenzymatic antioxidant defenses. The cells had been pretreated for $20 \mathrm{~h}$ with $3.0 \mathrm{mg} / \mathrm{mL}$ of intact milk protein and MRP, after which $500 \mu M t$-BHP were added for $3 \mathrm{~h}$. As shown in Figure 9 , the addition of $t$-BHP to the cells evoked a dramatic decrease in GSH compared with the control cells. However, the GSH depletion was overcome by pretreatment with MRP. Remarkably, the pretreatments of intact SC prevented GSH depletion to nearly the control value. Moreover, the pretreatment of G-cMRP showed the highest GSH level among all the samples by a considerable margin. With respect to its nonenzymatic defense, GSH is a tripeptide (glutamate, cysteine, and glycine) involved in the reduction of oxidant compounds. Thus, the intracellular stock of GSH plays an important protective role against oxidative stress (Scharf et al., 2003). Reduced glutathione depletion reflects intracellular oxidation, whereas an increase in GSH concentration could be expected to prepare cells against potential oxidative insults (Goya et al., 2007). In our study, a decrease in GSH concentration induced by $t$ BHP was prevented by pretreatment with the MRP, and G-cMRP in particular showed the highest level of prevention. Wang et al., (1997) reported that sulfur AA - cysteine and methionine (which can be converted to cysteine in the liver) - are the essential components for GSH synthesis, due to the limited availability of cysteine. Therefore, an adequate supply of these sulfur
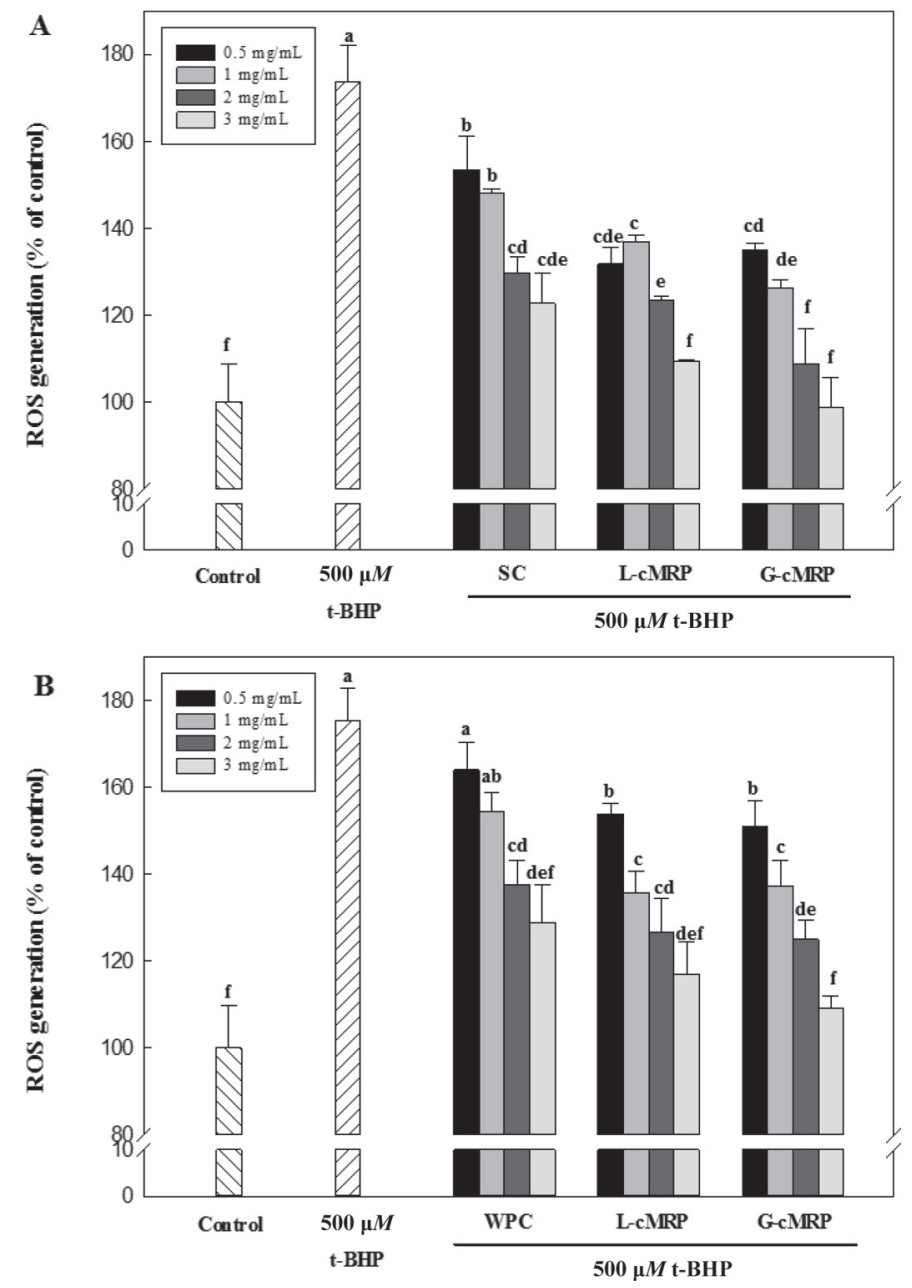

Figure 8. Protective effects of Maillard-reacted milk proteins (MRP) against tert-butyl hydroperoxide ( $t$-BHP) induced reactive oxygen species (ROS) generation in HepG2 cells. Cells were treated with MRP. After $20 \mathrm{~h}, 500 \mu M t$-BHP was added to all cultures, except for control, for $3 \mathrm{~h}$. The results are presented as mean $\pm \mathrm{SD}$ $(\mathrm{n}=3)$. Different letters $(\mathrm{a}-\mathrm{f})$ indicate statistically significant differences among the different groups $(P<0.05) . \mathrm{SC}=$ sodium caseinate; $\mathrm{L}-\mathrm{cMRP}=$ lactose-SC Maillard reaction products (MRP); G-cMRP $=$ glucose-SC MRP; WPC $=$ whey protein concentrates; L-wMP = lactose-WPC MRP; G-wMRP = glucose-WSC MRP.

AA is crucial for maintaining a normal hepatic GSH level (Wang et al., 1997). It has also been reported that methionine residues can act as antioxidants and scavenge many oxidizing molecules (Levine et al., 1996). From these results, it appears that the cytoprotective effect conferred by the MRP from milk protein against oxidative stress is due to their ability to prevent GSH depletion and increase GSH levels.

It has been reported that milk protein has a broad spectrum of functional effects, such as antimicrobial, antioxidative, antithrombotic, antihypertensive, and immunomodulatory activities (FitzGerald and Meisel, 2003, FitzGerald et al., 2004). For example, it has been 
reported that casein hydrolysates increased survival in rat hepatocytes (BRL cells) facing $\mathrm{H}_{2} \mathrm{O}_{2^{-}}$or galactosamine-induced injury via a correlation of antioxidant properties (Zhao et al., 2013). The present study indicates that MRP have protective effects on HepG2 cells, and that G-cMRP is the most effective in protecting HepG2 cells against $t$-BHP-induced oxidative injury. Moreover, as shown in the SDS-PAGE protein profiles and MALDI-TOF/MS spectra of the MRP in our study (Figures 3, 4, and 5), the major protein of WPC and $\mathrm{SC}$ was $\beta-\mathrm{LG}$ and $\alpha-$ and $\beta-\mathrm{CN}$, and the large molecular mass was increased after MR. Our previous study also confirmed the production of high-molecular weight MRP, measured by size-exclusion-fast protein liquid chromatography analysis of MRP (Oh et al., 2014). These results suggest that the new compounds derived from milk proteins might be related to their antioxidant activities and hepatoprotective effects.

\section{CONCLUSIONS}

In conclusion, Maillard-reacted milk protein combined with sugars resulted in an increase of fluorescence intensity and the generation of new compounds. The main modifications occurring in Maillard-reacted milk proteins were investigated with the MALDI-TOF/MS of partially digested proteins; the results suggest that

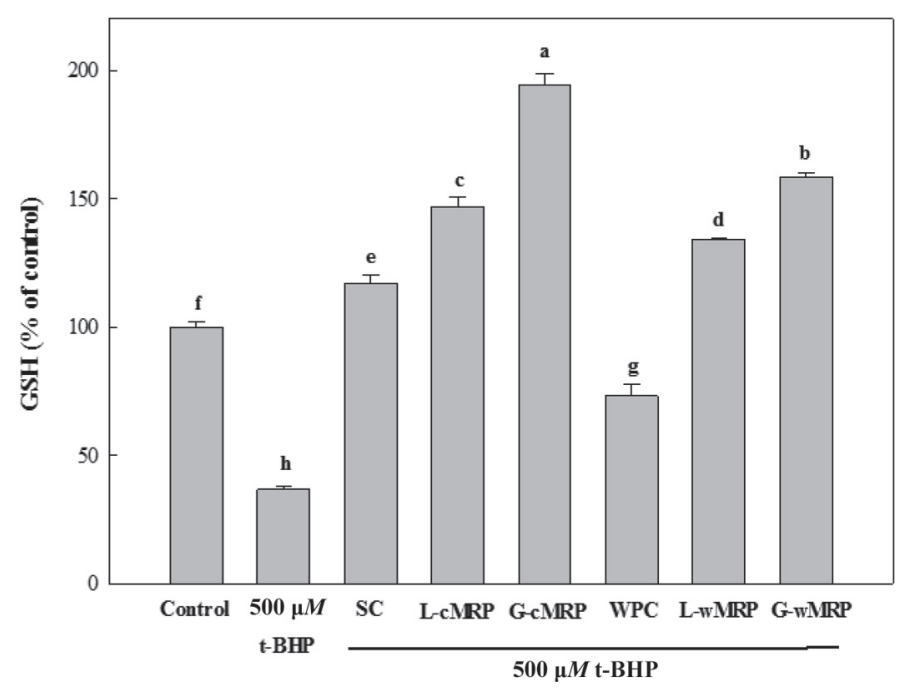

Figure 9. Protective effects of Maillard-reacted milk proteins (MRP) against tert-butyl hydroperoxide ( $t$-BHP) induced GSH in HepG2 cells. Cells were treated with MRP $(3.0 \mathrm{mg} / \mathrm{mL})$. After $20 \mathrm{~h}$, $500 \mu M t$-BHP was added to all cultures, except for control, for $3 \mathrm{~h}$. The results are presented as mean $\pm \mathrm{SD}(\mathrm{n}=3)$. Different letters $(\mathrm{a}-\mathrm{f})$ indicate statistically significant differences among the different groups $(P<0.05) . \mathrm{SC}=$ sodium caseinate; L-cMRP $=$ lactose-SC Maillard reaction products $(\mathrm{MRP}) ; \mathrm{G}-\mathrm{cMRP}=$ glucose-SC MRP; WPC $=$ whey protein concentrates; L-wMRP = lactose-WPC MRP; G-wMRP = glucose-WSC MRP. the main MR of WPC and SC with sugars occurred in $\beta-\mathrm{LG}, \alpha-\mathrm{CN}$, and $\beta-\mathrm{CN}$, respectively. The MRP derived from milk protein also showed higher radical scavenging activities and reducing power than intact milk protein. In addition, it was demonstrated that MRP have a protective effect against oxidative damage induced by $t$-BHP in HepG2 cells. Furthermore, the protective effect of MRP against $t$-BHP-induced GSH depletion seems to be an important factor in preserving cell viability. Compared with Maillard-reacted milk protein with lactose, Maillard-reacted milk protein with glucose exhibited greater biological effects. In particular, G-cMRP had the most antioxidative and hepatoprotective effects among the samples. These effects of the MRP formed using milk protein might be due to the synergistic actions of the compounds present in them and the MR. Overall, these MRP might have the potential for application in functional dairy products.

\section{ACKNOWLEDGMENTS}

This research was supported by the High ValueAdded Food Technology Development Program of the Korea Institute of Planning and Evaluation for Technology in Food, Agriculture, Forestry, and Fisheries (iPET, Gyeonggido, South Korea), and the Ministry for Food, Agriculture, Forestry, and Fisheries of Republic of Korea (Sejong Special Self-Governing City, South Korea; 111137-03-3-SB010).

\section{REFERENCES}

Apak, R., K. Güçlü, B. Demirata, M. Özyürek, S. E. Çelik, B. Bektaşoğlu, K. I. Berker, and D. Özyurt. 2007. Comparative evaluation of various total antioxidant capacity assays applied to phenolic compounds with the CUPRAC assay. Molecules 12:1496-1547.

Benjakul, S., W. Visessanguan, V. Phongkanpai, and M. Tanaka. 2005. Antioxidative activity of caramelisation products and their preventive effect on lipid oxidation in fish mince. Food Chem. 90:231-239.

Benzie, I. F., and J. Strain. 1996. The ferric reducing ability of plasma (FRAP) as a measure of "antioxidant power": The FRAP assay. Anal. Biochem. 239:70-76.

Blois, M. S. 1958. Antioxidant determinations by the use of a stable free radical. Nature 181:1199-1200.

Calvano, C. D., A. Monopoli, P. Loizzo, M. Faccia, and C. Zambonin. 2013. Proteomic approach based on MALDI-TOF MS to detect powdered milk in fresh cow's milk. J. Agric. Food Chem. 61:16091617.

Cucu, T., C. Platteau, I. Taverniers, B. Devreese, M. De Loose, and B. De Meulenaer. 2011. ELISA detection of hazelnut proteins: effect of protein glycation in the presence or absence of wheat proteins. Food Addit. Contam. Part A Chem. Anal. Control Expo. Risk Assess. 28:1-10.

Eyer, P., and D. Podhradský. 1986. Evaluation of the micromethod for determination of glutathione using enzymatic cycling and Ellman's reagent. Anal. Biochem. 153:57-66.

FitzGerald, R., and H. Meisel. 2003. Milk protein hydrolysates and bioactive peptides. Pages 675-698 in Advanced Dairy Chemistry-1 Proteins. Springer, New York, NY. 
FitzGerald, R. J., B. A. Murray, and D. J. Walsh. 2004. Hypotensive peptides from milk proteins. J. Nutr. 134:980S-988S.

Goya, L., R. Mateos, and L. Bravo. 2007. Effect of the olive oil phenol hydroxytyrosol on human hepatoma HepG2 cells. Eur. J. Nutr. 46:70-78.

Halliwell, B., J. Gutteridge, and C. Cross. 1992. Free radicals, antioxidants, and human disease: Where are we now? J. Lab. Clin. Med. 119:598-620.

Humeny, A., T. Kislinger, C.-M. Becker, and M. Pischetsrieder. 2002. Qualitative determination of specific protein glycation products by matrix-assisted laser desorption/ionization mass spectrometry peptide mapping. J. Agric. Food Chem. 50:2153-2160.

Knasmüller, S., W. Parzefall, R. Sanyal, S. Ecker, C. Schwab, M Uhl, V. Mersch-Sundermann, G. Williamson, G. Hietsch, and T. Langer. 1998. Use of metabolically competent human hepatoma cells for the detection of mutagens and antimutagens. Mutat. Res. 402:185-202

Laemmli, U. K. 1970. Cleavage of structural proteins during the assembly of the head of bacteriophage T4. Nature 227:680-685.

LeBel, C. P., H. Ischiropoulos, and S. C. Bondy. 1992. Evaluation of the probe $2^{\prime}, 7^{\prime}$-dichlorofluorescin as an indicator of reactive oxygen species formation and oxidative stress. Chem. Res. Toxicol. $5: 227-231$

Lederer, M. O., and H. P. Bühler. 1999. Cross-linking of proteins by Maillard processes - Characterization and detection of a lysinearginine cross-link derived from D-glucose. Bioorg. Med. Chem. $7: 1081-1088$

Levine, R. L., D. Garland, C. N. Oliver, A. Amici, I. Climent, A.-G. Lenz, B.-W. Ahn, S. Shaltiel, and E. R. Stadtman. 1990. Determination of carbonyl content in oxidatively modified proteins. Methods Enzymol. 186:464-478.

Levine, R. L., L. Mosoni, B. S. Berlett, and E. R. Stadtman. 1996. Methionine residues as endogenous antioxidants in proteins. Proc. Natl. Acad. Sci. USA 93:15036-15040.

Liggins, J., and A. J. Furth. 1997. Role of protein-bound carbonyl groups in the formation of advanced glycation endproducts. Biochim. Biophys. Acta 1361:123-130.

Liu, P., M. Huang, S. Song, K. Hayat, X. Zhang, S. Xia, and C. Jia 2012. Sensory characteristics and antioxidant activities of Maillard reaction products from soy protein hydrolysates with different molecular weight distribution. Food Bioprocess. Tech. 5:1775-1789.

Matiacevich, S. B., P. R. Santagapita, and M. P. Buera. 2005. Fluorescence from the Maillard reaction and its potential applications in food science. Crit. Rev. Food Sci. Nutr. 45:483-495.

Meltretter, J., S. Seeber, A. Humeny, C.-M. Becker, and M. Pischetsrieder. 2007. Site-specific formation of Maillard, oxidation, and condensation products from whey proteins during reaction with lactose. J. Agric. Food Chem. 55:6096-6103.

Mosmann, T. 1983. Rapid colorimetric assay for cellular growth and survival: Application to proliferation and cytotoxicity assays. J. Immunol. Methods 65:55-63.

Oh, N. S., H. Kwon, H. Lee, J. Joung, J. Lee, K. Lee, Y. Shin, S Baick, M. Park, and Y. Kim. 2014. Preventive effect of fermented Maillard reaction products from milk proteins in cardiovascular health. J. Dairy Sci. 97:3300-3313.

Oh, N. S., H. Lee, J. Lee, J. Joung, K. Lee, Y. Kim, K. Lee, and S. Kim. 2013. The dual effects of Maillard reaction and enzymatic hydrolysis on the antioxidant activity of milk proteins. J. Dairy Sci. 96:4899-4911.

Oh, N. S., M. R. Park, K. W. Lee, S. H. Kim, and Y. Kim. 2015 Dietary Maillard reaction products and their fermented products reduce cardiovascular risk in an animal model. J. Dairy Sci. 98:5102-5112.

Pinto, M. S., J. Léonil, G. Henry, C. Cauty, A. F. Carvalho, and S. Bouhallab. 2014. Heating and glycation of $\beta$-lactoglobulin and $\beta$-casein: Aggregation and in vitro digestion. Food Res. Int. 55:7076.

Rufián-Henares, J. A., and F. J. Morales. 2006. A new application of a commercial microtiter plate-based assay for assessing the antimicrobial activity of Maillard reaction products. Food Res. Int. 39:33-39.

Rush, G. F., J. R. Gorski, M. G. Ripple, J. Sowinski, P. Bugelski, and W. R. Hewitt. 1985. Organic hydroperoxide-induced lipid peroxidation and cell death in isolated hepatocytes. Toxicol. Appl Pharmacol. 78:473-483.

Scharf, G., S. Prustomersky, S. Knasmuller, R. Schulte-Hermann, and W. W. Huber. 2003. Enhancement of glutathione and g-glutamylcysteine synthetase, the rate limiting enzyme of glutathione synthesis, by chemoprotective plant-derived food and beverage components in the human hepatoma cell line HepG2. Nutr. Cancer 45:74-83.

Shevchenko, A., H. Tomas, J. Havli, J. V. Olsen, and M. Mann. 2006. In-gel digestion for mass spectrometric characterization of proteins and proteomes. Nat. Protoc. 1:2856-2860.

Stadtman, E. R., and R. Levine. 2003. Free radical-mediated oxidation of free amino acids and amino acid residues in proteins. Amino Acids 25:207-218.

Tiwari, A. K. 2004. Antioxidants: New-generation therapeutic base for treatment of polygenic disorders. Curr. Sci. 86:1092-1102.

Vidyashankar, S., S. Mitra, and K. S. Nandakumar. 2010. Liv. 52 protects HepG2 cells from oxidative damage induced by tert-butyl hydroperoxide. Mol. Cell. Biochem. 333:41-48.

Vitaglione, P., F. Morisco, N. Caporaso, and V. Fogliano. 2004. Dietary antioxidant compounds and liver health. Crit. Rev. Food Sci. Nutr. 44:575-586.

Wang, H., and J. A. Joseph. 1999. Quantifying cellular oxidative stress by dichlorofluorescein assay using microplate reader. Free Radic. Biol. Med. 27:612-616.

Wang, S.-T., H.-W. Chen, L.-Y. Sheen, and C.-K. Lii. 1997. Methionine and cysteine affect glutathione level, glutathione-related enzyme activities and the expression of glutathione S-transferase isozymes in rat hepatocytes. J. Nutr. 127:2135-2141.

Wang, W. Q., B. Yi-hong, and C. Ying. 2013. Characteristics and antioxidant activity of water-soluble Maillard reaction products from interactions in a whey protein isolate and sugars system. Food Chem. 139:355-361.

Yoshimura, Y., T. Iijima, T. Watanabe, and H. Nakazawa. 1997. Antioxidative effect of Maillard reaction products using glucose-glycine model system. J. Agric. Food Chem. 45:4106-4109.

Zhao, X.-H., Y. Fu, and N. Yue. 2013. In vitro cytoprotection of modified casein hydrolysates by plastein reaction on rat hepatocyte cells. CyTA J. Food 12:40-47. 